\title{
Web-Based Learning in Qatar and the GCC States
}

Alan S. Weber

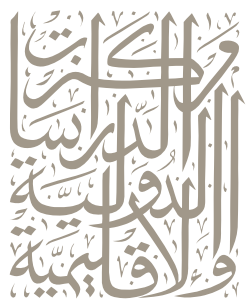

CIRS

CENTER FOR

INTERNATIONAL

AND REGIONAL

STUDIES

GEORGETOWN UNIVERSITY

SCHOOL OF FOREIGN SERVICE IN QATAR

(C) 2010 


\section{Web-Based Learning in Qatar and the GCC States}

Alan S. Weber

(C) 2010 Center for International and Regional Studies

Georgetown University School of Foreign Service in Qatar

Occasional Paper No. 5

ISSN 2072-5957 


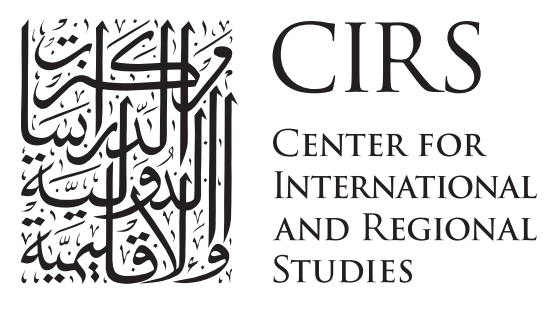

GEORGETOWN UNIVERSITY SCHOOL OF FOREIGN SERVICE IN QATAR

Established in 2005, the Center for International and Regional Studies at the Georgetown University School of Foreign Service in Qatar is a premier research institute devoted to the academic study of regional and international issues through dialogue and exchange of ideas, research and scholarship, and engagement with national and international scholars, opinion makers, practitioners, and activists.

Guided by the principles of academic excellence, forward vision, and community engagement, the Center's mission revolves around five principal goals:

- To provide a forum for scholarship and research on international and regional affairs

- To encourage in-depth examination and exchange of ideas

- To foster thoughtful dialogue among students, scholars and practitioners of international affairs

- To facilitate the free flow of ideas and knowledge through publishing the products of its research, sponsoring conferences and seminars, and holding workshops designed to explore the complexities of the twenty-first century

- To engage in outreach activities with a wide range of local, regional and international partners. 


\title{
Web-Based Learning in Qatar and the GCC States
}

\author{
Alan S. Weber
}

Alan S. Weber joined the Weill Cornell Medical College in Qatar (WCMC-Q) as a faculty member in the Pre-medical Program in 2006. Weber previously taught literature, writing, and the history of science and medicine at Cornell University, Ithaca; State University of New York, Binghamton; The Pennsylvania State University; and Elmira College. His research interests include language, history, and the social and cultural dimensions of science and medicine. He is the editor of 19th Century Science (2000), and Because It's There: A Celebration of Mountaineering Literature (2001), and is the author of specialized publications on Shakespeare, women in medicine, and 17th century medicine. He was a pioneer of electronic learning as a graduate student at The State University of New York, Binghamton, in the early 1990s. 



\section{Foreword}

Qatar is a small peninsula in the Gulf that borders the Rub-al-Khali desert and is near the islands of Bahrain, with which Qatar has shared a mutual political history. The Emir of Qatar, HH Sheikh Hamad bin Khalifa Al-Thani, and his consort HH Sheikha Mozah Bint Nasser Al-Missned, have over the past 10 years directed billions of dollars of public expenditures toward improvements in Qatar's education and health care systems. Developing a technologically advanced post-hydrocarbon knowledge economy in which egovernment, e-business, and e-learning play important developmental roles, is a key component of this overall development strategy. The leadership of Qatar has clearly recognized the general role of education in diversifying the economy and stimulating business growth outside of the petroleum and gas industries that currently dominate the economic landscape: according to the World Economic Forum, the leading "most problematic factor for doing business in Qatar" is the "inadequately educated workforce" (Government of Qatar Planning Council 2007, 15).

This contribution grew from my interests in electronic pedagogy which began at the State University of New York (SUNY), Binghamton, during the rise of the Internet in the early 1990s when Bulletin Boards and e-mail became standard business and educational tools, and graphics-based web browsers were developed along with reliable plain-text protocol chat technology such as Internet Relay Chat (IRC). In 1996-97, I bundled these emerging technologies into an experimental completely on-line course titled Electronic Shakespeare (Shakespeare being my primary area of scholarly expertise), along with the chemistry courses of my colleague and distance education guru Wayne Jones, also at SUNY, Binghamton. Electronic Shakespeare was one of the first on-line courses offered at that institution.

I never marketed this product, held together as it was with duct tape, string, and chewing gum, because more robust and more elegantly programmed Course Management Systems (CMS) such as Blackboard and WebCT appeared at the same time and rapidly took hold (in 2006, business rival Blackboard acquired WebCT, and acquired Angel Learning Systems in 2009). The ability of course management systems to accurately enroll, manage, grade, and track large numbers of students became evident to large educational institutions, but the software was also accompanied by a great deal of hype and unproven claims. In fact, in light of the over-stated capabilities of webbased educational solutions, my interest in Internet-based education flagged 
in the late 1990s, and I returned to more traditional pedagogies at Pennsylvania State University and Cornell University. I nevertheless maintained a continuing interest in e-learning in my literature and history of medicine and science courses.

When I began teaching at Weill Cornell Medical College-Qatar in 2006, I witnessed the explosion of Internet-based learning across the Gulf region. Simultaneously, I also saw much of the same rhetoric, and the same mistakes that confronted us in the early to mid-1990s. Most prominent was the 'panacea' approach being promulgated by Gulf Cooperation Council (GCC) governments who were jumping on the e-learning bandwagon. E-learning would solve illiteracy, alleviate poverty, create better citizens through e-government, and help to build advanced knowledge-based societies. E-learning can certainly help to achieve many of these goals, but the click of a mouse will not make years of underfunding in education, lower than average research and development investment, disjunctions between Gulf educational systems and the labor market, reliance on a traditional pedagogical model of memorization, and low Internet penetration rates and low computer literacy (acute in the North African regions of Middle East North Africa (MENA)) disappear overnight. Significant challenges lie ahead in the region such as course accreditation, the creation of Arabic language learning objects, the equitable distribution of technology goods and services, and the tempering of idealistic expectations of what e-learning can actually accomplish. Consequently, I began a comprehensive overview study of e-learning in the GCC countries for the International Association of Science and Technology for Development (IASTED) (2009a).

In spring 2009 I conducted experimental research on Arabic language speakers' use of three leading course management systems: Blackboard, Moodle, and Angel. Through a technology notebook, and a detailed endof-semester questionnaire, students tracked their difficulties and successes in each virtual learning environment through exercises in synchronous chat, asynchronous bulletin board discussion groups, electronic peer editing, and electronic resource access.

The GCC countries, in particular the United Arab Emirates (UAE), Qatar, and Saudi Arabia, have made large investments in e-learning resources during the past five years. Support and development of e-government schemes are also widespread in the Gulf. E-learning in the region is often intimately linked to larger overall Information and Communication Technology (ICT) strategies to integrate technology and computers into all sectors of Gulf econ- 
omies. In addition, telemedicine, remote robotic surgery, and e-health (which employ the same communications technologies and protocols of e-learning) are now poised to make a quantum leap into everyday medical reality in the west. The GCC countries, now committed to high standards of patient care, will soon follow suit. Qatar's new Sidra Hospital, slated to open in 2012 with a $\$ 7.9$ billion (USD) permanent endowment, will be a fully digital hospital with an advanced Electronic Medical Records (EMR) system.

This study is based on a review of the relevant published literature on e-learning and discussions with colleagues and experts throughout the Gulf region. Every effort has been made to incorporate the most up-to-date data and statistical figures as of September 2009; any inaccuracies in this paper are solely the responsibility of the author. 


\section{Acknowledgments}

I would like to thank Dr. Vladimir Uskov for his assistance, and WCMC-Q Deans David Robertshaw, Javaid Sheikh, and Michael Johnson, for their support. Dr. Benjamin Reilly provided valuable information on teleconferencing activities in Education City, and Gregory Jenkins of the College of the North Atlantic-Qatar provided additional comments. The publications of ictQatar are the source of essential information on the topic, as are the educational reports of RAND-Qatar Policy Institute (RQPI). Anthony McCourt of ictQatar provided information on Qatar e-health initiatives. 


\begin{abstract}
This contribution surveys the historical development and current state of e-learning in Qatar and the GCC states, including the educational, political, social, and financial factors that led to the adoption and development of current systems and initiatives. Although significant challenges have arisen in the use of e-learning technologies, such as general computer literacy, interoperability and cross-platform issues associated with the flood of learning objects on the market, the lack of Arabic language learning objects, and Internet bandwidth and reliability, e-learning is poised to usher in considerable educational changes in the learning populations of the Gulf region. In the face of declining hydrocarbon reserves in some Gulf nations, this paper analyzes the ways in which e-learning initiatives have been designed to help create the post-oil knowledge economies, which Gulf rulers hope will propel GCC countries into the top tier of technologically advanced societies in the world.
\end{abstract}

\title{
Introduction: E-Learning in Qatar and the GCC
}

Qatar has rapidly moved to the forefront of e-learning ${ }^{1}$ among the GCC countries (Qatar, Bahrain, Saudi Arabia, Oman, Kuwait, and the United Arab Emirates). Not only has ictQatar, the Internet regulatory and development arm of the Qatari government, rolled out an impressive array of electronic resources in local elementary and high schools in the last two years, but the American branch campuses in Qatar Foundation's Education City have been using teleconferencing technology to connect main campuses with branch campuses to deliver the most up-to-date live lectures by faculty in specialized fields of medicine, political science, and history. Qatar has a concrete national strategy to develop a knowledge society, including the development of the Information and Communication Technologies (ICT) sector focusing on e-learning, e-government, telecommunications, the creation of Qatar Foundation to advance higher education, K-12 curricular reforms based on RAND

\footnotetext{
${ }^{1}$ The terms on-line education, web-based education, and e-learning are difficult to define since each of these terms can refer to education and training that is delivered entirely by computer networks or local area networks (LANs), or delivered in conjunction with brick and mortar classroom instruction. On-line instruction can take place purely on-line, with the students and instructor never meeting, or can be delivered by electronic means combined with traditional face-to-face interactions in what is called blended learning. In this paper, e-learning is defined simply and broadly as instruction delivered via the Internet, with or without face-to-face interaction. This definition is generally synonymous with the term web-based education. E-learning offers several proven advantages over traditional instruction in a classroom and also can augment traditional pedagogical approaches.
} 
Qatar Policy Institute recommendations, the dedication of \$19 million (USD) in 2009 to biotechnology research, the creation of the Qatar Science and Technology Park (QSTP) for commercial development of innovative technologies originating in Qatar, and Qatar's target of dedicating 2.8\% of total gross domestic product (GDP) to research by 2010 . Other GCC countries also have pursued significant national government investment strategies in e-learning resources, which are often packaged and delivered on the same websites as e-government services.

Although some Gulf nations in the past five years have made tremendous gains in international ICT indicators, the Middle East as a region ranks third from the bottom in percentage of the population using the Internet, and the distribution of resources is highly uneven. The UAE leads the GCC with $59.6 \%$ of its population using the Internet. The other Gulf nations, except for Oman, which at $13.7 \%$ is well below the world average of about $23 \%$ usage, are classified as countries possessing a medium Internet penetration rate with Saudi Arabia at 25.1\% (2008), Bahrain at $34.8 \%$ (2008), and Kuwait at 33.4\%. Both Qatar (52.3\%) and the UAE, however, are now classified as highly penetrated countries (Internet World Stats, June 2009 [except as noted]).

But these statistics can be misleading and may not reflect how the Internet is actually being used in the GCC. Speaking of the GCC as a whole, Elango et al. warn that "actual [Internet] penetration into homes and actual usage in workplaces and schools remain very limited" (2008,33-34). For example, according to ictQatar, while $43 \%$ of employees in super large and large businesses use a personal computer (PC) in the workplace, only $35 \%$ are provided with a business e-mail address. And only $1 / 4$ of all businesses in Qatar used advanced Internet services such as e-banking and e-commerce, compared with almost $2 / 3$ of the companies in the European Union (EU) (ictQatar Landscape 2009, 23-24).

The Gulf nations operate in a traditional educational paradigm that relies heavily on passive learning and rote memorization techniques. This has fostered a strong dependence on the instructor in the learning process. The first public school building opened in Qatar in 1950, and the first institution of higher learning, Qatar University (QU), opened in 1977 (Mohammad 1992, 21-28; Brewer 2006, 4). Prior to the expansion of public schools in the 1950s and 60s, a select few could attend the Khutub schools which focused on memorization of passages of the Qur'an, along with some mathematical learning (Naji 1976, 160-73). As Heji has pointed out, education in Qatar "remained traditional until 1995" when the current Emir assumed power and later inaugurated with his wife the educational reform program titled Education for a New Era, which stresses school autonomy, accountability, variety, and choice (Heji 2007,3).

Dr. Mohammed E. Al Ansari, former manager of e-Education at ictQatar, has 
alluded to a new pedagogical model that e-learning can facilitate in which students are active and not passive learners: "e-Education will not replace teachers, but will support them to adopt new pedagogical skills in alignment with the new role of facilitating, supervising and managing students' learning, rather than just being a source of information" (Nurturing 2007, 21).

Developing curricula around the collaborative aspects of e-learning, such as synchronous chat and bulletin boards, may prove very valuable for cooperationbased societies. This pedagogy, not unique to e-learning, 'flattens' the classroom; it can also make use of peer mentoring which greatly enhances the learning of both tutor and tutee, and may take some pressure off instructors as the sole means of knowledge dissemination.

The research of Saudi educator Dr. Reima Al-Jarf has revealed some student resistance to autonomous e-learning, which is understandable in the context of Gulf educational traditions. After an analysis of her on-line EFL course at Umm AlQura in 2005, Al-Jarf concluded that the students "felt that the Internet should be used for fun, not for credit or as a proper course. As a result, they did not take it seriously. They were passive rather than active learners" (Al-Jarf 2007).

A significant body of educational and business research exists on the pedagogical adaptations required in transnational education at branch and offshore campuses in China and southeast Asia based on the work of G. Hofstede (1986, 2001). Hofstede makes a very broad but useful distinction between individualistic (generally western) and collectivist (Asian) cultural, educational, and work norms, but much work remains in understanding the cultural dynamics that impact education on transnational campuses in the Gulf region, despite the surprising fact that 29\% of all branch campuses worldwide are located in Qatar and the United Arab Emirates (Rumbley and Altbach 2007, 4; Reilly 2008; Weber 2009a; Prowse 2007). E-learning presents a perfect opportunity to study cultural differences in learning styles, classroom behavior, the cross-cultural impact of learning objects, and instructional approaches-for example, e-learning can exemplify autonomous learning (a learner's independent completion of on-line modules) and collectivist (collaborative) learning, such as the Flat Classroom Project at Qatar Academy where students in groups designed and implemented multi-media projects about current global issues. Also, course management systems such as Angel and Blackboard can automatically capture educational data, such as quiz scores, attendance, homework grades, etc., for educational research.

Another significant advantage of e-learning is the "anytime, anywhere" aspect of e-learning, which allows learners to access materials when they are ready to learn, to learn at their own pace, to customize the selection of learning objects to meet their individual learning styles, and to repeat learning exercises. This is the key positive 
feature of the e-learning modality that is most often cited in surveys, reports, and research articles. For some learners with busy and inflexible work schedules or for house-bound users, e-learning may be their only option for education. There is an extensive body of educational research on this topic in the West which cannot be summarized here. The fact that e-learning had been previously validated in America and Europe by peer-reviewed scholarly research, however, undoubtedly was a contributing factor in its rapid adoption in the GCC, and lowered many barriers to its acceptance among educators in the region.

A further advantage is that pre-packaged learning and training modules can be disseminated over computer networks at extremely low costs to large numbers of learners. However, initial development costs for customized, specialized learning materials (since they are prepared by specialists) can rival or even exceed the costs of traditional pedagogical materials such as textbooks. Thus far, the greatest cost efficiency has been achieved in information technology (IT), business, and basic computer skills modules. E-learning also reduces travel time, expense, and time away from work for employee training.

\section{Maintaining Gender Separation}

E-learning's ability to transcend traditional brick and mortar classrooms shows great promise in the more socially conservative Wahabi-influenced nations-Qatar, Saudi Arabia, and UAE-where women and men do not normally intermix socially outside of the family unit. Western educators working in the Gulf, particularly those in co-educational branch campuses of American, British, Canadian, or Australian universities, consistently underestimate the impact and implications of this deeply rooted Gulf custom. Co-educational institutions represent only a tiny fraction of Gulf schools at all levels of education, and much of the educational research published in English emanates from these elite co-educational schools, providing a distorted picture of Gulf education.

Gender segregation in the Gulf is not a trivial issue-Gulf inhabitants generally concur that gender separation is sanctioned by the Holy Qur'an, related to the principle of hijab in its extended symbolic sense of modesty and privacy beyond its more common meaning of veiling and covering. Although in Qatar women are receiving university degrees in higher numbers than men, and $\mathrm{HH}$ Sheikha Mozah has sponsored numerous workshops and conferences to promote female business ownership, the questions of the professional woman and women in the workplace (similar issues to women in the mixed gender classroom) have not been fully resolved. The 2004 census revealed that only $29 \%$ of Qatari females participate in the national labor force, as opposed to $68 \%$ of males. One reason may be that "many Qatari women are reluctant to work in jobs that require them to spend long hours 
at work and away from their families or that involve working in a mixed-gender environment" (Berrebi 2009, 432).

The vast majority of primary and secondary schools and the major Gulf universities (and students themselves) continue to practice some form of gender separation either through separate boys' and girls' schools, separate courses, physically separate campuses such as Qatar University, or classroom seating arrangements. Some Western educators have argued that this gender segregation negatively impacts male education at the primary level: "[GCC] government schools are segregated overwhelmingly by gender: boys are taught by men, girls by women. Since positions in education, including those of classroom teachers, are generally less attractive to men, there is a shortage of teachers for boys. As a result, boys' schools often employ lower-calibre teachers-and, sure enough, the GCC gender gap in student outcomes is among the most extreme in the world" (Barber 2007, 43).

The fact remains that many Gulf families and women are more comfortable in a gender-separated environment. Many Gulf women cite such benefits of the practice as the continuity of traditional cultural norms, freedom from harassment, special banking and postal areas and queues, and the unique female bonds and friendship system that develops. The female-only Zayed University in the UAE has developed a wireless Internet-enabled campus that may benefit female students who prefer to limit their interactions with male professors, since course assistance is generally readily available on-line through e-mail (Lansari et al. 2007). On-line tools may encourage female students to overcome their traditional reticence in mixed gender groups. A. Heble, an educator at Sultan Qaboos University in Oman, writes that: "The use of on-line tools certainly seems to have encouraged [my female Omani students] to formulate and express their opinions and to communicate with their male counterparts at a level that would probably be unthinkable in a face-to-face educational situation" (Heble 2007).

Al-Jarf in Saudi Arabia, on the other hand, has demonstrated how the virtual environment for first time e-learners is not necessarily a safe, 'other' world where cultural boundaries can be explored: "My female students were shy, apprehensive and hesitant to register, others wanted to conceal their identity by registering using a male's name, using their first name and initials, deleting their e-mails, or using 'anonymous' instead of their real names" (Al-Jarf 2007). One Gulf educator, Adekunle Akinyemi, an instructor at United Arab Emirates University, fears that "the interactivity factor in web based learning poses an obvious threat to the Arab culture and religion. ... Can or should students' [on-line] groupings be organized to avoid the mixed (MF) mode? Can the communications tools be structured and closely monitored to completely eliminate 'love and romance' in web-sessions?" (Akinyemi 2003, 1862). This fear has also been raised by three Kuwaiti educators in that e-learning systems 
designed in the west may not be appropriate for the Islamic context: "Interaction in the virtual realm is faceless and knows no restrictions in terms of race, color, sex, religion etc. A cultural conflict may thus emerge as the interaction patterns cannot be easily controlled between the male and female students" (Al-Hunaiyyan et al. 2008, 20).

\section{Advantages for Disabled House-Bound Users}

Disabled learners are a particular concern in Qatar, which suffers from one of the highest motor vehicle accident (MVA) rates in the world. MVAs are the number one cause of childhood deaths and morbidity in children under 14 in Qatar (Al-Kilani et al. 2002; El Tawil et al. 2002; Bener 2005). However, disabled persons are not often seen in public because of a mixed tradition in Islam toward disability. Studies from Oman, Egypt, Lebanon, Jordan, and Yemen all report that the disabled face discrimination in all walks of life in those countries (Abdul-Haq 2008, 117-123).

E-learning provides excellent educational opportunities for learners who do not wish to appear in public due to congenital malformation or disability for fear of stigmatization and negative social attitudes. Assistive computer technologies, such as the Lomak (Light Operated Mouse and Keyboard), footmice, trackballs, etc., and Augmentative and Alternative Communication (AAC) have grown enormously in sophistication and reliability, and allow an increasing number of the disabled to not only access on-line information and learning, but also to create and communicate information, promising a more active learning environment for them. Creating computer-based learning systems accessible to the disabled will be a key factor in integrating the disabled fully into Gulf societies. For example, an estimated 720,000 Saudis (4\% of the population) suffer from some form of disability, and yet an estimated $90 \%$ of websites and $98 \%$ of e-government sites are inaccessible to the disabled (Abanumy et al. 2005, 99). Qatar is directly addressing this issue and plans to develop a Center for Assistive Technology in the near future to sponsor research and development in assistive technologies.

\section{The Effectiveness of E-Learning}

Most important, e-learning appears to increase favorable learner outcomes as opposed to traditional learning methods which do not employ technology, according to a recent 2009 United States (US) Department of Education study which conducted a meta-analysis of over 1000 empirical studies of e-learning from 1996 to 2008 (Means et al. 2009). The study concluded: "The meta-analysis found that, on average, students in online learning conditions performed better than those receiving faceto-face instruction" (Means et al. 2009, ix). However, two previous meta-analyses by Cavanaugh (2001) and Bernard et al. (2004) found no significant differences in 
distance education and face-to-face instructional modalities. But the large data sets and careful definition of variables makes the 2009 study persuasive. Given these findings, and taking into account the often lower costs associated with on-line learning, many institutions, particularly at the community college level, have invested substantially in e-learning resources in the US, integrating them into larger on-line registration and student records systems. Due to the novelty of e-learning in the Gulf, published data-driven outcomes assessments have been rare both at the secondary school and university level, compounded by the fact that educational systems in many GCC countries, specifically Qatar, are undergoing major reforms. Previous educational outcomes data from traditional schools is often sparse, incomplete, or not benchmarked to meaningful international standards, preventing an accurate comparison between earlier pedagogies and e-learning. As part of national strategy visions in Oman, Qatar, and Saudi Arabia, e-learning development is intertwined with upgrading the government's ICT capacities (networks, hardware, general computer literacy) for accurately capturing statistical data, such as educational statistics, that could be used in e-learning research and policy making.

One way to increase the impact and effectiveness of e-learning is to incorporate technological themes and troubleshooting skills explicitly into the course and provide lectures or demonstrations on the technologies behind the interfaces (which students even of a young age generally have no trouble using): for example, short html code writing exercises, theories of networks, protocols, etc. YouTube.com has many short documentaries on various aspects of Internet technologies and Wikipedia pages can be valuable in explicating how networked computers function and communicate with each other. The use of e-learning can therefore increase facility with technology, especially if the on-line instructor makes the learner a partner in diagnosing and troubleshooting the many technical issues that are still plaguing the seamless delivery of e-learning in the Gulf. Current e-learning technologies employ some of the same basic protocols, software tools, and interfaces that will power both current and futuristic technologies such as exocortices, the Semantic Web, virtual simulation systems, 3-D optical holographic data storage, etc. This strategy, however, requires a very high technical proficiency on the part of the instructor.

With a pedagogical model that was validated over ten years ago, and internationally adopted (the majority of large universities in the world have some e-learning component in their curricula), the question remains as to why the GCC has been slow to adopt e-learning until quite recently, when interest in e-learning has grown almost exponentially in countries like Qatar and the UAE. One obvious reason is that there have been substantial infrastructural Internet and telecommunications problems in the region, as well as reluctance (technophobia) to embrace such a powerful entity as the Internet, which has caused rapid and profound 
cultural, economic, and social change in other parts of the world. In the GCC, the effects of e-learning have yet to take shape, provided that these countries overcome the numerous barriers to the implementation of assistive learning technologies.

\section{Barriers to E-Learning Adoption and Development in the GCC}

\section{Telecommunications Market Monopolies}

Telecommunications markets, generally controlled by individual Gulf governments, have only very recently been opened to competition. Oman's Omantel, the incumbent provider, has undergone partial privatization over the last five years. Qatar's Qtel recently allowed Vodafone to enter the market.

The lack of competitive telecommunications markets in the region results in substantial Internet usage fees, which limits access to on-line learning resourcesan important consideration in very populous countries like Saudi Arabia, and also a concern in less wealthy countries such as Oman and Yemen. Saudi students exposed to e-learning have cited high Internet usage fees as an important factor when choosing to take an on-line course (Alzamil 2006). According to the United Kingdom (UK) analyst firm Point Topic, while United States broadband consumers pay an average of $\$ 16$ per megabit per second of download speed, consumers in the Middle East pay more than $\$ 46$ per megabit per second (Arnold 2008).

The high cost of service combined with computer illiteracy has created a sizable digital divide in Arabic-speaking countries (most pronounced in MENA countries). However, due to large increases in disposable income in Gulf nations with substantial hydrocarbon reserves, the digital divide is rapidly decreasing in Qatar, Kuwait, Saudi Arabia, and the UAE. But, according to ictQatar, the cost of broadband Internet in Qatar is still too high for the lowest income stratum which constitutes the largest segment of society (Qatar's ICT Landscape 2009, 8). Also, "the average number of PCs available for educational purposes is only 8.3 PCs per 100 students...Furthermore, the PC-to-student ratio in Europe is almost 1.5 times that of Qatar and the percentage of schools with PCs in the classroom in Europe is nearly 3.5 times the percentage observed in Qatar's schools" (Qatar's ICT Landscape 2009, 37).

Qatar's ICT development program also faces challenges in adequately training teachers to use emerging digital technologies: "Less than half of all teachers in Qatar's schools -44 percent-received any form of ICT training in the 12 months ending by the end of school year 2007-2008" (Qatar's ICT Landscape 2009, 41). Most of this training involves certification in the International Computer Driving License (ICDL) program which teaches basic skills and applications such as word processing and spreadsheets. To address growing regional demand for computer literacy, the European Computer Driver's License Foundation approved the ICDL 
GCC Foundation in 2004 as a regional partner to coordinate its certification programs. In addition, the Doha Declaration of The Asian Cooperation Dialogue (which includes all GCC countries) in May 2006 expressly endorsed e-education efforts via the Asia e-University as "an instrument for human capacity building, closing the digital divide, increasing access to higher education" (Asia Cooperation Dialogue 2006).

Further, on-line education in the Arabic-speaking world has been hampered by the lack of Arabic language learning objects and materials. As Laaser points out, "Arabic language web pages form a dismal 0.1 percent of the entire content of the Web, though Arabic speakers constitute five percent of the world's population" (Laaser 2006, 148). English is the primary language of e-learning systems, and prominent Islamic scholar Sheikh Yusuf al-Qaradawi, a resident of Qatar since 1961, is alarmed about the effects of English language education in Islamic countries. AlQaradawi recently said publicly "that sending children to schools using a foreign language [English] as its medium of instruction would only 'produce a generation alienated from its Arabic and Islamic roots"' (Elshamy 2009, 1). He believes that the consequences will be that children in Qatar will grow up with a British perception of the world.

Even the Arab Open University (AOU) in Kuwait, a leader in distance education, "depends profoundly on [United Kingdom Open University] materials, consultancies, and so forth, leaving no room to develop home-grown materials" (Mohamed 2005). Many of the on-line courses taught at Syrian Virtual University (est. 2002) in Damascus are taught in English, especially those courses delivered by partner universities. Blackboard's recent introduction of an Arabic language interface is a positive step toward generating more Arabic language e-learning content.

\section{Maintaining Quality Standards in E-Learning and Cyber-Safety}

National educational standards, assessment, and quality control of on-line materials have lagged in the Gulf region, specifically with respect to ensuring that course materials are sensitive and relative to the Arab world context (Alsunbul 2002, 73). Lack of e-learning quality standards, however, is also an international concern, not unique to the Gulf. These concerns were raised in 2002 in a UNESCO report: "Higher education authorities seem to be absent from regulating providers of higher learning that are outside the mainstream of the education system, such as corporate institutions and providers of education opportunities through non-traditional delivery means, i.e. open learning, e-learning, virtual universities, etcetera" (UNESCO 2002, 9). A.A.H. Mohamed has argued persuasively that Syrian Virtual University and Arab Open University are in the best position to offer leadership in standards and accreditation for regional endeavors in distance and e-learning (Mohamed 2005).

GCC nations are concerned about misuses of the Internet, such as children 
accessing inappropriate content, libel, fraud, hacking, etc; and, e-learning, specifically classroom chats and e-mail, can introduce additional threats to children such as cyber-stalking and bullying in unsupervised electronic environments. Qatar Computer Emergency Response Team (Q-CERT) is addressing these potential problems and Qatar will actively cooperate with the ITU's international Child Online Protection initiative. IctQatar will also develop a special site on the e-government portal Hukoomi to keep parents and teachers informed of emerging cyber-risks to children, and ways of combating those risks. GCC educators have cited risk to children and inappropriate content, both sexual and religious (Saudi Arabia, for example, actively blocks websites proselytizing other religions), as two of the major roadblocks to more widespread use of the Internet in the GCC, and therefore a barrier to on-line learning initiatives. In order to maintain quality standards for the future of e-learning, Qatar has created an entire infrastructure in support of these new initiatives.

\section{Web-Based Learning in Qatar}

Through royal decree, Qatar established the Supreme Council of Information and Communication Technology (ictQatar) in 2004 to create ICT sector policy, foster development, and regulate emerging communications technologies. Similar to other Gulf ICT planning endeavors, ICT resource development is part of the Qatar National Vision for 2030. ICT is expected to impact all sectors of Qatar's government and economy, and information will be available to all citizens through centralized portals—for example, many government services are already organized under the single portal Hukoomi (www.gov.qa).

Qatar has made impressive advancements in all areas of ICT performance in the region: "Qatar now ranks among the top three in the Arab world in terms of combined performance in basic ICT indicators such as the numbers of computer users, Internet users, mobile telephone, fixed telephone lines, and broadband Internet subscribers" (Qatar's ICT Landscape 2009, 7). In 2005, Qatar was ranked 40 ${ }^{\text {th }}$ in the world in the World Economic Forum's Networked Readiness Index, but jumped to 29th in 2008-09 (Networked Readiness 2009).

According to ictQatar's Secretary General Dr. Hessa Al-Jaber, e-education in Qatar will "support an individualized and flexible learning environment through technology. A technology-rich learning community is envisaged, where parents, students, and teachers have timely access to information, where teacher-student communication transcends time and geography, and where research and development are seamlessly integrated. Classrooms will be transformed into global learning centers, linking homes, schools, and society, so education truly happens anywhere, anytime" (Al-Jaber 2008, 139). 
The 2007 commissioned RAND report titled Education for a New Era: Design and Implementation of K-12 Education Reform in Qatar revealed some structural and organizational deficiencies in Qatar's K-12 system (Brewer 2007). E-learning initiatives, which had begun several years earlier, soon became part of an ambitious overall strategy to upgrade the education system in Qatar.

RAND recognized several problems, which e-learning as a new pedagogy (which has attempted throughout its development to incorporate current western 'best practices' in education) could in some ways alleviate: "absence of a coherent vision of education goals; a hierarchical organizational structure within the Ministry of Education; an outdated curriculum that focused on rote memorization; lack of innovation in the classroom; no authority to make decisions at the school level; no systematic appraisal of student outcomes" (Gonzalez et al. 2008, 65). E-learning emphasizes learner participation and the creation of knowledge communities, i.e., interactive and active learning which fosters innovation, personal ownership of knowledge, and the application of knowledge to real-world situations, instead of the repetition and transmission of received wisdom. The "banking model" of education, in which learning is passively "poured into" the student by the teacher, although an effective practice for the large "101"-type lecture course which provides necessary facts and background introduction to a field of knowledge, now has very little support in advanced education in the west, but is still a dominant Gulf education paradigm. As Gregory Jenkins, IT instructor at College of the North AtlanticQatar has pointed out, e-learning is not just a new means of education delivery, but also a new mode of learning that creates excitement and engagement in the classroom: "E-learning is personalized and empowers the students. When this type of technology is brought into the classroom the result is an exciting and motivating environment. It improves student engagement and educational outcomes. Students drive teaching innovation, which accelerates the use of technology, and thus enhances student learning" (Jenkins to Weber 2009).

One of the earliest e-learning initiatives of ictQatar was eSchoolbag launched at Al Wakrah Independent School for Girls in 2006. Seventh grade students all received Tablet PCs containing programs for digital note-taking and searching, as well as e-content in math and science mapped to current Qatari curriculum standards (Elearning Project 2006). Qatar University has also embraced e-learning, and the Blackboard learning management system is now available at QU. In 2005, a group in QU's Department of Engineering and Computer Science, including Fayed F. M. Ghaleb, Sameh S. Daoud, Ahmad M. Hasna, Jihad M. Jaam, and Hosam F. El-Sofany, developed an e-learning system for teaching basic computer and programming courses. The programmers were dissatisfied with current products such as Blackboard and open-source products to fit their particular educational needs 
(2006). This same group experimented with Semantic Web applications in e-learning to make web data more intelligent, and more machine readable and interoperable. Dr. Adil Yousif (2007) also taught Elementary Statistics in an e-learning format at Qatar University and Naser-Nick Manochehr conducted research on e-learning styles at the same university in 2006.

The overall goals of the introduction of e-learning systems in Qatar are similar to those in other Gulf nations: deliver Rich Learning Experiences (RLE), enhance academic achievement, develop self-directed learners, and train an effective teacher corps (ictQatar 2008). Specifically, in the primary and secondary education system, ictQatar and the Supreme Education Council are pursuing the development of Knowledge Net (K-Net).

Knowledge Net is a learning management system portal based on Microsoft Learning Gateway that allows for three-way communication between parents, students, and teachers. The technology company ITWorx will customize the Microsoft system with new English and Arabic interfaces, and phase it into Qatar's independent school network. Parents, students, and teachers can log in from anywhere to access not only basic information and tools such as calendars, events and news, school policies, and student planners, but also access e-mail, chat, discussion groups, and document storage, which can all be used as new pedagogical tools for new collaborative learning environments. Knowledge Net was launched in twelve Qatari schools in 2006-07 and the final Phase III of the project is slated to be introduced in 2010-11 to approximately 300 Qatari schools administered by the Supreme Education Council. By scaling e-learning system deployment in a stepwise fashion, Qatar is obviously trying to avoid the mistakes made by other Gulf nations where systems were adopted immediately without adequate assessment of both technical and human resources, and an understanding of the instructor skill levels required, before implementing new technologies.

Qatar's closely related future e-health plans involve electronic health records (discussed below) to speed up health information flow, such as laboratory test results, consultations, and sharing diagnostic images and facilitating medical appointments and scheduling. Facility with e-learning technology learned in primary and secondary schools will make Qatari citizens more adept users of the e-health services which will soon be available. IctQatar has set a 2010 target date for implementation of its e-health portal and services. To satisfy the strict privacy requirements in personal medical information, particularly data transmitted over the Internet, ictQatar is working with Carnegie Mellon University's Q-CERT to manage all manner of cybersecurity risks including fraud, unauthorized computer access, and data misappropriation.

E-learning and ICT development in Qatar has been carried out with remarkable 
transparency. Public statements and mini-lectures from ictQatar are regularly published and available on YouTube.com, and ictQatar has developed a public consultation process on new initiatives (see the ictQatar website). For example, ictQatar solicited public input on its future policies for licensure of Very Small Aperture Terminal (VSAT, or "satellite dishes") providers, and then published on its website ictQatar's responses to the comments.

\section{Education City, Qatar-Teleclasses, and Other E-Learning Initiatives}

Georgetown University maintains state-of-the-art Polycom RPX (RealPresence Experience) "telepresence" facilities at its Qatar campus and on the main campus in Washington, D.C. These include 16 foot video screens that create a "true-tolife" interaction between classrooms. Georgetown jointly runs one or two "bi-local" classes per semester with an instructor from one of the campuses and students from both. This allows the Qatar campus to expand its curriculum with electives not offered by faculty in Qatar. It also increases the visibility of the Georgetown University School of Foreign Service in Qatar with students and faculty on the main campus. Moreover, students on both campuses meet regularly through the RPX room (outside of the formal classroom) for dialogue about relations between the US and the Middle East.

Weill Cornell Medical College in Qatar (WCMC-Q) has also made considerable use of teleclasses because of a shortage of faculty to teach some of the very specialized material required in medical education. Cornell originally agreed with Qatar Foundation that it would provide the exact same curriculum as in New York City. The New York City main campus dean Antonio Gotto reported that "the [Qatar Foundation] said 'we'll pay for it. You do it exactly as you would in New York" (Bollag 2006, 6). Live teleconferencing has helped to achieve this goal of curriculum parity. Before the introduction of teleclasses, students were instructed by a mixture of Qatar campus faculty and taped lectures from New York City faculty.

WCMC-Q is equipped with technology-rich lecture halls. Each lecture hall at $\mathrm{WCMC}-\mathrm{Q}$ is "equipped with an integrated system of electronic teaching tools controlled from the lectern, and audio response system and laptop connectivity for students. Three rear projectors allow for simultaneous use of a variety of resources. Facilities include advanced communications and $\mathrm{A} / \mathrm{V}$ solutions, Internet access, and provision for CD, VCR and DVD presentations"(WCMC-Q, 2009). One course in the Premedical program, Introductory Psychology (Psych 101), is taught in a blended learning approach by Dr. James Maas from Ithaca, New York, via teleconference, while a Teaching Assistant in Qatar assists with student questions and concerns, and proctors exams.

Teleclasses have proved to be more cost efficient than constantly flying over 
medical experts from the main campus in New York to teach small specialized tutorials to small groups of students (Weber 2010).

Carnegie Mellon University in Qatar (CMU-Q) in Education City makes similar use of teleclasses. At CMU-Q, Dr. Benjamin Reilly developed a history course titled "Inward Odyssey" which integrates e-learning into the course theme of Christian and Muslim travel literature. American students at the Pittsburgh main campus and Gulf students at the Qatar campus of Carnegie Mellon University confront each other much in the same way as travelers to other cultures encountered new peoples. Reilly explains, "When I chose to offer Inward Odyssey as a teleconferencing class...I almost exclusively assigned travelogues in which Moslems or Arabs travel into Christian lands, or vice versa. As a result, the journeys made by the travel writers into the lands of the 'other' mirrors the classroom experience of the students themselves, generating lively and highly productive discussion" (Reilly 2008, 6).

Texas A\&M University at Qatar (TAMU-Q) students have 24/7 access to the Office of Academic Supplemental Instruction Services (OASIS) comprised of an Advanced Writing Center which hosts a variety of e-learning resources for English language learning, including grammar podcasts, handouts, and a dedicated language lab for computer-assisted English language practice. E-learning is also one of the delivery methods which will be used for advanced petrochemical training and management at TAMU-Q under a recent agreement with Schlumberger, Inc., through the Network of Excellence in Training (NExT). The NExT network, now numbering over 250 virtual faculty, offers "subject-specific modules, e-learning (computer-based training), and blended learning (tutorial-led and computer-based training)... and multilingual Web-based learning in exploration and production fundamentals" (Texas AEM Engineering Nerws 2008). The network exemplifies one of the most productive uses of e-learning in the Gulf region--delivering highlyspecialized technical knowledge from physically distant expert sources to a very small target learning population.

CMU-Q, established in 2004, offers the Bachelor of Arts degree in computer science and therefore has been actively involved in all aspects of e-learning, including teleclasses, development of educational computer software, and electronic outreach to developing nations. For example, undergraduate Noura Mohammed El-Moughny and Professor M. Bernadine Dias have been developing an electronic adaptive Braille writing tutor for blind Arabic speakers (2008). CMU-Q's TechBridgeWorld organization founded by Professor Dias is involved in a number of international technology transfer projects involving e-learning, specifically the Education e-village. E-village will make on-line course materials, syllabi, and reading lists for CMU-Q's courses such as “Technology for Developing Communities,"“Technology and Global 
Development," and "Understanding and Challenging the Images of Computing" available on the Internet to partners in Ghana, Zambia, the Cook Islands, China, and Micronesia.

CMU-Q's recently introduced program called innovative Student Technology ExPerience (iSTEP) allows students to apply existing computer technologies to solve unique small-scale community problems. The 2009 projects in Tanzania include "developing a mobile phone application for use by social workers to track information on services provided to AIDS orphans and vulnerable children, creating and evaluating culturally-relevant educational technology and games for children's literacy and enhancing and evaluating a low-cost Braille writing tutor for visuallyimpaired students" (TechBridgeWorld 2009).

In April 2009, TechBridgeWorld organized the 3rd International Conference on Information and Communication Technologies for Development (ICTD 2009) in conjunction with ictQatar. Bill Gates (chairman of Microsoft Corporation, and co-chairman of the Bill and Melinda Gates Foundation) and Carlos A. Primo Braga (director of Economic Policy and Debt in the Poverty Reduction and Economic Management (PREM) Network at The World Bank) spoke at this meeting. Because of extremely low Internet penetration rates and rarity of computers in many parts of Africa, technology transfer non-governmental organizations (NGOs) such as TechBridgeWorld have been investigating the cell phone and personal digital assistant (PDA) as a potential educational tool. Lack of Internet infrastructure, small screen size of the devices, and low data transfer rates are known barriers for delivery of educational modules, particularly if they are graphics-intensive. However, smallscale mobile phone banking and agricultural pricing and marketing systems (using Short Message Service (SMS)), have become a reality in parts of Africa.

Qatar's technical college, College of the North Atlantic-Qatar (CNA-Q), has been heavily involved with e-learning training, promotion, and research by sponsoring the annual ICT in Education Conference in 2008 and 2009, co-sponsored by ictQatar. Over 500 participants attended the 2009 conference, indicating the great interest in this area.

Using Wikispaces and Ning, Vicki Davis of Westwood Schools in the US and Julie Lindsay of Qatar Academy in Education City developed The Flat Classroom Project which brings together middle school and high school students in virtual space and "flattens the classroom." The concept for this e-learning project came from Thomas Friedman's influential and popular book The World is Flat.

\section{Medical Applications of Electronic Technologies in Qatar}

In the next few years, several of Qatar's major medical institutions will begin operations, including the Sidra Medical and Research Center (SMRC), and the 
Qatar Robotic Surgery Center. These facilities include extensive plans for innovative use of e-learning and related technologies. The Sidra Medical and Research Center will be one of the largest, most complicated, and capital-intensive health projects ever undertaken in the Gulf. The hospital will be an all-digital, state-of-the-art hightech hospital with a $\$ 7.9$ billion USD permanent endowment.

When Sidra hospital opens in 2012, all employees will need to be experienced users of web-based applications. The hospital will boast an advanced Electronic Medical Record (EMR) system. Although Australia and the UK have built successful national EMR systems (approximately $70 \%$ to $90 \%$ usage rates among general practitioners (GPs)), use of fully functional EMR systems in the US may be as low as $17 \%$ to $25 \%$, and the American Recovery and Reinvestment Act of 2009 suggests that institutions and doctors should prioritize the development of EMR systems (Bates 2003; Burt 2005, 1; DesRoches 2008).

Oman introduced the EMR in 2000 and now 70\% of Omani hospitals use an EMR system. Although doctor satisfaction with the system is generally high due to such benefits as reducing redundancy in prescriptions and tests, and reducing medical error (for example, adverse drug reactions), some complaints are that the system is time-consuming, does not protect patient confidentiality adequately, and that the continuing use of paper records adds to practitioners' workload (redundant inputting of data into both paper and electronic medical records) (Al Farsi and West 2006).

It is imperative that the first physicians to use the EMR system at Sidra have some higher-level network and computer skills in order to troubleshoot and maintain this ambitiously envisioned system. In fact, Sidra project managers have incorporated a period of commissioning to confirm that all systems and installations at Sidra are fully operational and "there will also be several months of training for the Center staff to ensure they can fully utilize the technologies and can effectively function in an all-digital environment" (Project Update 2009). In keeping with the all-digital philosophy of the hospital, the means of instructional training in these electronic systems (patient records, digital pharmacy, ordering, planning, etc.) will inevitably be partially web-based.

Telemedicine or e-health essentially involves the movement of health information over electronic networks and can take the form of public health advice on websites, teleconsultations between medical professionals or doctors and patients by telephone or videoconferencing, or the capture and transmission of diagnostic data (CT or X-ray images, output from pulse oximeters, blood pressure units, etc.) for a variety of purposes. The implications of e-health for international medical school branch campus e-learning, clerkship, and training are enormous and obvious. Teleconferencing can substitute for face-to-face doctor/patient consultation, 
and a new array of tele-diagnostic technologies, such as the digital otoscope, the digital stethoscope, and high resolution patient examination cameras, may one day partially alleviate the lack of fully-trained onsite doctors in remote regions (Weber and Musson 2010). Dr. Jacques Marescaux in the US and France has also been experimenting with a wireless videoconferencing mobile robot for telementoring surgeons-in-training as an alternative to local onsite instruction (Sereno et al.2007), which could have immediate benefits for Gulf medical education.

The Qatar Robotic Surgery Center, which should become fully operational some time from 2010 to 2012 with three da Vinci surgical robots and ten laparoscopic simulators will also make use of e-learning teleconferencing technologies for teaching and demonstration. The center is building a simulated operating theater and a tele-mentoring suite to be used for transmitting 3-D live robotic surgeries for learning purposes, theoretically to any medical student or surgeon in the world via the Internet.

Also in Qatar, the chief biomedical research advisor for SMRC, David Kerr, is exploring the use of mobile phones for the delivery of e-health information: "We will exploit the electronic media to support our clinical trials. Another interesting idea is to use e-health through mobile phones because almost everybody in Qatar has one" (Olayiwola 2009).

As the health system of Qatar advances, it is critical that medical professionals be connected to the most up to date information on biomedical advances in the more technologically developed countries. On-line Continuing Medical Education accomplishes this goal and is a regular feature of professional development at WCMC-Q. Several times per semester, live or recorded teleconferences on topics relevant to medical education are streamed to WCMC-Q professors and Hamad Medical Corporation practitioners, followed by question and answer periods.

In the US, licensure laws require that physicians demonstrate they are regularly updating their medical knowledge and skills. Increasingly, companies such as CMEweb.com and GE Healthcare are able to offer on-line continuing medical education credits through web-based tutorials and other electronic means. In Qatar, Continuing Medical Education (CME) credits are factored into promotion, renewal, and licensing at the Hamad Medical Corporation, and in 2007, UAE physicians, nurses, and medical technicians were required to maintain a certain number of CME credits per year for re-licensing (Renewal 2006). Saudi Arabia also requires by law that all medical and paramedical professionals maintain a certain number of CME credits per year. In light of these new job requirements developing throughout the Gulf, e-learning will become an increasingly attractive option for these already busy medical professionals for fulfilling CME requirements, as it reduces travel time and time away from the workplace to attend training workshops and symposia. 


\section{What E-Learning Cannot Do in Qatar}

Several education scholars and international reports have argued that there is a mismatch between technical and vocational education in Qatar, and both national economic demands and the aspirations of Qatari youth. From 1977 to 2001, over $70 \%$ of secondary and $73 \%$ of university graduates in Qatar studied literature and related fields, which could lead to lucrative public sector employment. This trend contributed to a shortage in science and technical workers (Jolo 2007). In a recent RAND report, the authors argued that "Secondary school graduates [in Oman, Qatar, UAE, and Lebanon] are considered unprepared to directly enter the labor market with relevant skills or to enter competitive university programs" (Gonzalez et al. 2008, xx). Another RAND report on the Qatari labor market concluded that "patterns of education and employment among Qataris are somewhat misaligned with demand. This is especially true for males: Qatari men continue to pursue careers in fields other than those in demand-most notably the military and police...." (Stasz 2007, xv). Addressing this situation obviously involves educational policy, but e-learning may play a small role in making learning in general more attractive, and more useful and targeted for Qatari youth, particularly since any activity involving technology will have a perceived higher status among younger learners. The computer skills learned using e-learning are also directly applicable to almost any kind of professional employment.

Two very real barriers to e-learning adoption that ictQatar has identified, that e-learning itself can probably not solve (although education about ICT and e-learning may make an impact), include lack of inter-ministerial cooperation and collaboration, and technophobia. Dr. Al-Jaber, Secretary General of ictQatar, explained parental anxiety concerning the use of computers and the Internet (technophobia):

In Qatari society, the issue of inappropriate content on the Internet is a huge barrier to wholesale adoption of the technology. Some parents resist children's Internet use, and a wide technological divide exists between children and their parents. Although parents can protect their children physically from negative influences, they feel vulnerable when it comes to the Internet. So, although many e-education initiatives are technologically and pedagogically effective, children may not enroll because of parental anxiety. To offset these barriers to successful adoption of technology, Qatar offers parents and teachers training and e-security programs (A1-Jaber and Dutta 2008, 141).

In conclusion, e-learning can address some of the education, training, and labor market challenges that crop up consistently in international and national reports 
and discussions of the Gulf education systems-large expatriate work forces, lack of coordination between education and private business needs, over reliance of nationals on public sector employment, and large youth unemployment, particularly in Qatar. But obviously, education policy, structuring, organization, and pedagogical philosophies must all be re-examined in an attempt to address fully these concerns. Currently, these issues are also being addressed in the other GCC states, and many have invested in and activated particular e-learning plans.

\section{E-Learning in the Other GCC Countries}

\section{Saudi Arabia}

The Kingdom of Saudi Arabia (KSA) has approached e-learning and the Internet in general with some trepidation. Public access to the Internet was only allowed in 1999 and by 2000 there were only about 200,000 Internet users throughout the KSA. In 2008 Saudi Arabia ranked 46th out of 70 in the Economist Intelligence Unit's e-Readiness index (Economist 2008, 5). But Saudi Arabia's investment in e-learning is substantial: the Madar Research Group estimated that the e-learning industry in Saudi Arabia reached \$125 million USD in 2008 and would continue to grow thereafter at a compound annual rate of $33 \%$ over the next five years (MENAFN 2008).

The Technical and Vocational Training Corporation of Saudi Arabia offers a wide variety of on-line courses through their e-learning and Training Resources Center. Part of the national labor force strategy (Saudization) hopes to train more skilled native graduates to replace the over 7 million expatriate workers in the country. Except for Oman and Saudi Arabia, foreign workers substantially outnumber the local population in the Gulf nations (for example, in both Qatar and the UAE, only approximately $20 \%$ of the population holds citizenship). The underlying strategic thinking therefore behind linking e-learning with government subsidized education may be to increase a locally trained labor force without increasing the number of foreign national teachers. It is doubtful that e-learning, however, can provide immediate or long-term solutions to this and other serious education issues in Saudi Arabia such as large government education expenditures without adequate returns (24\% of government spending in 2003 was devoted to education in Saudi), lack of science and engineering graduates (only 18\% of higher education students in these fields), lack of cooperation between education and private enterprise, and negative attitudes of the local population to service industry training and employment (Bosbait 2005).

Many Saudi students are concerned about course accreditation for on-line courses since some e-courses cannot be taken for credit. Ali et al. surveyed science students at the King Fahd University of Petroleum and Minerals in 2003 and discovered that 
the "majority of the respondents prefer not to take courses on the Internet...these courses are not considered equivalent to regular courses in the country and moreover on-line courses are not accredited in the country" (Ali et al. 2003, 9).

\section{United Arab Emirates}

Dubai boasts a high Internet penetration rate, and large growth rates in its e-learning initiatives. Madar Research Group estimates that total spending on e-learning in the UAE grew 26\% in 2008 and will reach $\$ 72.6$ million (USD) by the end of 2010 (Al Bawaba 2008).

Course Management Systems (CMS) are now de rigueur in the Emirates' colleges and schools (Hussein 2007, 37). At United Arab Emirates University, the number of Blackboard CMS users jumped from 1200 in 2002 to 8000 by 2005 (Guessoum 2006). Responding to this expanding regional market, primarily in Saudi Arabia and the UAE, in 2006-07 Blackboard developed its first all-Arabic language interface running on Blackboard Learning Platform 7.x. This development may help to mitigate the barrier, cited in numerous studies as a key concern, of the use of English language software and learning objects at Arabic-speaking universities.

Most important, the UAE has been leading the region in research and assessment of e-learning systems witnessed by the large number of published peer-reviewed articles emanating from such educational institutions as United Arab Emirates University, Zayed University, Al-Ain University of Science and Technology, University of Sharjah, British University in Dubai, Higher Colleges of Technology, Dubai Men's College, Dubai Women's College, and The Petroleum Institute of Abu Dhabi, which are all experimenting with on-line learning technologies. Whether the recent global downturn, which has significantly impacted Dubai (over 50\% of construction projects cancelled and defaults on international loans), will increase or decrease the use of electronic educational resources remains to be seen.

\section{Kuwait}

The Kuwaiti educational system has largely been rebuilt since the devastating 1990 Iraqi invasion and subsequent oil fires. Kuwait has applied its tradition of participatory and consultative government (shura) to developing its e-learning initiatives from the ground up. Gulf educational systems are often extremely hierarchical: education policy is set at the highest levels of administration, with little or no input from teachers or even middle managers. A 2006 Aldhafeeri et al. study of Kuwaiti e-learning details how teachers were directly recruited for a national e-learning strategy (see also Weber 2009a). Aldhafeeri et al. note:

Teachers' involvement in fostering the e-learning environment in schools was encouraged. Letters were sent to every school in Kuwait urging teachers to make 
contributions to the e-learning project through submitting educational software, electronic materials and lessons, or even ideas to enrich the development of an e-learning system. These contributions were collected and rearranged by the Center of Information Technology at the Ministry of Education of Kuwait.

E-learning developments in the business sector in Kuwait have sparked some criticism. For example, Salah Al-Fadhli of Kuwait University and owner of the AlAwlamaa e-learning company believes that the quantitative (cost-saving aspects) of e-learning have been emphasized and researched too much in the business community, but unfortunately e-learning has been underutilized in providing a new pedagogical paradigm emphasizing critical thinking skills for the Arabic language university (A1-Fadhli 2009, 221). Al-Fadhli's perspective is unique since it spans both the business and academic worlds.

Similarly, according to a study by Kuwait Maastricht Business School, e-learning may have been introduced too rapidly into Kuwaiti businesses without the usual development cycle of planning and system design, integration, then improvement and quality control. Many Kuwaiti business since 2000 have apparently moved directly into integrating e-learning systems ('bandwagon' approach) without the requisite support and training, which obviously compromises the effectiveness and quality of such initiatives (Ali and Magalhaes 2008, 36).

\section{Oman}

Digital infrastructure and e-learning plays a large role in Oman's Vision for Oman's Economy: Oman 2020. The current seventh Five Year Development Plan (200610) for Oman emphasizes upgrading the ITC capabilities of the country as part of a national strategy for Oman's Digital Society (ESCWA 2007, 6). The national telecommunications provider Omantel has launched the Easy Learning Service providing hundreds of on-line training courses in accounting, sales, marketing, and customer services. The Al Huda Private School provided the first proof of concept of the fully-wired electronic educational institution in Oman (Sultanate of Oman 2007, 56). Similar to the other Gulf nations, Oman launched an electronic educational portal on its main e-government website in 2008.

The US Department of State's Middle East Partnership Initiative (MEPI) collaborated with the Omani Ministry of Education on the Oman Online Teacher Training (OOTT) initiative in 2006-07. The program sought to demonstrate the possibility of training Omani teachers by electronic means.

Course management system software use has grown rapidly in Oman: Sultan Qaboos University (SQU) began using WebCT in 2001 with eight on-line courses and 981 users, which increased in 2002 to 40 courses and 3001 students. The College of Applied Sciences increased its Blackboard usage from 15 on-line courses and 
581 users in 2007, to 30 courses and 890 students in fall 2008 (Al-Senaidi et al. 2009, 576; Al-Musawi and Abdelraheem 2004; Al-Musawi 2007). SQU instructors with some science background are generally convinced of the positive aspects of e-learning, according to a 2005 survey (A1-Khanjari 2005).

A 2008 survey of 100 faculty members at the College of Applied Sciences, however, uncovered serious barriers to the use of technology in education, including teachers' lack of preparation time (the main barrier cited by teachers), and teacher resistance to technology use, possibly arising from "poorly designed software, technophobia, doubt that technology improves learning outcomes, and fear of redundancy" (Al-Senaidi et al. 2009, 576).

\section{Babrain}

Oil was first struck in the Gulf in Bahrain, and an extensive modern public school system based on British models developed there beginning in 1919. Bahrain has taken the next step beyond delivering e-content, and has developed the Distance Teaching and Training Program for the College of Graduate Studies at Arabian Gulf University to produce teachers who can create and administer on-line content. According to Kandil, "The program aims at preparing the cadre that is capable of designing, implementing, maintaining, and managing distant learning systems" $(2004,1)$. The Arabian Gulf University in partnership with the University of Sunderland, UK, also offers entirely on-line the Post Graduate Certificate in Education (PGCE), consisting of 34 weeks of on-line tutorials, forums, and video material managed by WebCT. Teaching practicums for teachers-in-training are assessed either by a site visit from the Sunderland mentor, or through the submission of a videotaped teaching session, which means that the certificate can be completed entirely on-line without a face-to-face meeting. Bahrain's eGovernment Authority and the Bahrain Internet Society also offer an annual eContent Award to the best new electronic learning application.

In March 2007, the e-Learning Center opened at the University of Bahrain under a grant of BD 300,000 from MTC-Vodafone (Bahrain). The center currently offers about 150 e-courses tailored to the $\mathrm{B}$ ahraini learner, has sponsored a conference on Gulf e-learning in 2008 and has hosted such events as live video-conferencing with Georgetown University, Washington, DC, on the topic of media coverage of the Iraq War (Manibo 2007).

A branch campus of the Arab Open University (UK Open University affiliate) opened in Bahrain in 2003. The Open University of Malaysia also offers the MBA degree through AOU, Bahrain. Via the www.taaleem.org website, postgraduate and undergraduate on-line learning courses are available at the University of London and the University of Portsmouth. 
A growing number of private Bahraini companies believe that embracing e-learning provides clear and measurable financial benefits, substantially reducing training delivery costs through volume delivery, reducing lost time in the workplace, and cutting down on the travel, administration, and accommodation expenses for sending their professional workforce outside the country for training. As a significant financial center of the Middle East, Bahrain has considerably developed its electronic banking capacities.

As with all Gulf countries, Bahrain faces the very serious problem of lack of educational quality assurance in the e-learning arena (Moussa and Moussa 2008, 2). Also, success rate data (number of enrolled students, degrees awarded, postgraduate placement) of on-line programs in Bahrain and in the Gulf region in general are difficult to obtain, due to the newness of the programs and the difficulty of obtaining statistics from governments or private companies running the programs.

\section{Conclusion}

E-learning technology and programs are relatively new throughout the Gulf region. Qatar, a late entrant into the development of ICT technologies, has rapidly moved, however, beyond the "panacea" (e-learning will solve all educational problems) and "bandwagon" (everyone else in the Gulf is doing it) approaches to e-learning prevalent in the earlier e-learning adoption strategies of other Gulf nations, and has thus far avoided the indiscriminate purchase of e-learning systems and premature implementation models without proper planning and support. The phased introduction of K-Net in Qatari schools, for example, follows international best practices for system implementation. Qatar's investments in general education at all levels, the development of Education City, Qatar Science and Technology Park, etc. all indicate that the goal of creating a knowledge-based economy goes beyond mere rhetoric.

Instead of importing knowledge from western countries, Gulf nations like Saudi Arabia and Qatar who are investing in advanced educational infrastructure and bold initiatives, such as genetic medicine and embryonic stem cell research, will soon become exporters of technical knowledge. Due to the political framework of the GCC and the strong cultural ties and common social, religious, and economic concerns, e-learning technologies will be instrumental in regional knowledge development and sharing. The educated elite in the Gulf are fully aware of Islam's former international domination of science, technology, and medicine during the early Middle Ages, and now armed with massive petroleum revenues, GCC governments are serious about rebuilding the Muslim knowledge base in all areas of endeavor. Of considerable interest to GCC governments are both information networks (delivery) and content (knowledge itself). E-learning has piggy-backed on Gulf governments' 
initial interest in e-commerce (particularly banking and credit) and e-government portals to provide better government assistance to citizens and to aid in collecting census and health data for government planning. Widely viewed in the region as mutually reinforcing e-government and overall technological literacy, e-learning will experience substantial growth in the next decade in the areas of training and education in the GCC. As Gulf nations face the prospect of declining hydrocarbon reserves, many Gulf rulers have fully endorsed a variety of technologically-aided learning initiatives that will help to shape the future of diversified knowledge-based economies. 


\section{REFERENCES}

Abanumy, Abdulmohsen, Ali A1-Badi, and Pam Mayhew. 2005. E-government website accessibility: In-depth evaluation of Saudi Arabia and Oman. Electronic Journal of e-Government 3 (3):99-106.

Abdul-Haq, A. K. 2008. Disability. In Caring for Arab Patients: A Biopsychosocial Approach, ed. L.S. Nasir and A.K. Abdul-Haq, 117-124. Abingdon: Radcliffe.

Akinyemi, A. 2003. Web-based learning and cultural interference: Perspectives of Arab students. In Proceedings of World Conference on E-Learning in Corporate, Government, Healthcare, and Higher Education 2003, ed. G. Richards. Chesapeake, VA: AACE.

Al Bawaba. 2008. UAE's E-learning Market Grows by 26 percent to Reach USD 72.6 Million by 2010. http://www1.albawaba.com/en/news/uae's-e-learningmarket-grows-26-cent-reach-usd-726-million-2010 (accessed April 8, 2010).

Aldhafeeri, Fayiz, Mohammed Almulla, and Bandar Alraqas. 2006. Teachers' expectations of the impact of e-learning on Kuwait's public education system. Social Behavior \& Personality: An International Journal 34 (6):711-728.

Al-Fadhli, S. 2009. Instructor perceptions of E-learning in an Arab country: Kuwait University as a case study. E-Learning 6 (2):221-229.

Al Farsi, M. and D. J. West, Jr. 2006. Use of electronic medical records in Oman and physician satisfaction. Journal of Medical Systems 30 (1):17-22.

Al-Hunaiyyan, A., Nabeel Al-Huwail, and Salah Al-Sharhan. 2008. Blended e-learning design: Discussion of cultural issues. International Journal of Cyber Society and Education 1 (1):17-32.

Ali, S., S. M. Sait, and K. M. A1-Tawil. 2003. Perceptions about eLearning in Saudi Arabia. Paper presented at the International Council of Associations for Science Education, April 7-10, in Penang, Malaysia.

Ali, G. E. and R. Magalhaes. 2008. Barriers to implementing e-learning: a Kuwaiti case study. International Journal of Training and Development 12 (1):36-53.

Al-Jaber,H. and S. Dutta.2008. Qatar: Leveraging technology to create a knowledgebased economy in the Middle East. Global Information Technology Report 2007-2008 133-143. World Economic Forum.

Al-Jarf, R. 2007. Cultural issues in online collaborative instruction in EFL 
classrooms. In Proceedings of the Third International Online Conference on Second and Foreign Language Teaching and Research, March 2-4.1-7.

Al-Khanjari, Z. A., N. S. Kutti, and A. S. S. Dorvlo. 2005. Preparedness for the introduction of e-learning in higher education-The case of Oman. Journal of Social Sciences 1 (2):92-98.

Al-Kilani, H. H. et al. 2002. Road traffic accidents: The first childhood killer. Middle East Journal of Emergency Medicine 2, no. 2 (September) http://www.hmc.org.qa/ mejem/ (accessed April 8, 2010).

Al-Musawi, A. S. 2007. Current status of educational technologies at Omani higher education institutions and their future prospective. Educational Technology Research and Development 55 (4):395-411.

Al-Musawi, A. and A. Abdelraheem. 2004. E-learning at Sultan Qaboos University: Status and future. British Journal of Educational Technology 35 (3):363-67.

Al-Senaidi, S., Lin Lin, and Jim Poirot. 2009. Barriers to adopting technology for teaching and learning in Oman. Computers E Education 53 (3):575-590.

Alsunbul, Abdulaziz. 2002. Issues relating to distance education in the Arab world. Convergence 35 (1):59-80.

Alzamil, Zakarya A. 2006. Students' perception towards the e-learning at the GOTEVOT and the Arab Open University in Riyadh. Journal of King Saud University: Educational Sciences E Islamic Studies 18 (2):1-44.

Arnold, T. 2008. GCC broadband 'too expensive' says Du CEO. ArabianBusiness. November 12. http://www.arabianbusiness.com/537919-gcc-broadband-tooexpensive-says-du-ceo (accessed September 8, 2009).

Asia Cooperation Dialogue. 2006. Doha Declaration, on the occasion of the 5th Asian Cooperation Dialogue ministerial meeting, Doha, Qatar, 24 May. http://www.acddialogue.com/download/key_document/105.pdf (accessed April 8, 2010).

Barber, M., Mona Mourshed, and Fenton Whelan. 2007. Improving education in the Gulf: Educational reform should focus on outcomes, not inputs. McKinsey Quarterly 39-47. http://www.mckinseyquarterly.com/Improving_education_in_ the_Gulf_1946 (accessed April 8, 2010). 
Bates, David W. et al. 2003. A proposal for electronic medical records in US primary care. Journal of the American Medical Informatics Association 10 (1):1-10.

Bener, A. 2005. The neglected epidemic: Road traffic accidents in a developing country, State of Qatar. International Journal of Injury and Safety Promotion 12 (1):45-47.

Bernard, Robert M. et al.2004. How does distance education compare with classroom instruction? A meta-analysis of the empirical literature. Review of Educational Research 74 (3):379-439.

Berrebi, C., Francisco Martorell, and Jeffery C. Tanner. 2009. Qatar's labor markets at a crucial crossroad. The Middle East Journal 63 (3):421-42.

Bollag, B. 2006. America's hot new export: Higher education. The Chronicle of Higher Education (February 17), http://chronicle.com/article/Americas-Hot-NewExport-H/24719/ (accessed 25 August 2009).

Bosbait, M. and R. Wilson. 2005. Education, school to work transitions and unemployment in Saudi Arabia. Middle Eastern Studies 41 (4):533-545.

Brewer, Dominic J. et al. 2006. An introduction to Qatar's primary and secondary education reform. RAND Working Paper. Santa Monica, CA: RAND.

2007. Education for a New Era: Design and Implementation of K-12 Education Reform in Qatar, Santa Monica, CA: RAND.

Cavanaugh, C. 2001. The effectiveness of interactive distance education technologies in K-12 learning: A meta-analysis. International Journal of Educational Telecommunications 7 (1):73-78.

DesRoches, C. M. et al. 2008. Electronic health records in ambulatory care-A national survey of physicians. New England Journal of Medicine 359 (1):50-60.

Economist. 2008. E-readiness rankings 2008: Maintaining momentum. http:// a330.g.akamai.net/7/330/25828/20080331202303/graphics.eiu.com/upload/ibm_ ereadiness_2008.pdf (accessed April 8, 2010).

Elango, R., V. Gudep, and M. Selvam. 2008. Quality of e-learning: An analysis based on e-learners' perception of e-learning. The Electronic Journal of e-Learning 6 (1):31-43. 
El-Moughny,N.M.and M.B.Dias.2008.Assistive computing technology forlearning to write Braille. Undergraduate Senior Thesis. Carnegie Mellon University in Qatar.

Elshamy, A. 2009. Qaradawi sees threat to Arab identity. Gulf Times. April 4. $\quad$ http://www.gulf-times.com/site/topics/article.asp?cu_no=2\&item_ no=285318\&version=1\&template_id=57\&parent_id=56 (accessed April 8, 2010).

El-Sofany, Hosam F. et al. 2006. A web-based e-learning system experiment. International Journal of Computing and Information Sciences 4 (1):22-29.

ElTawil,M. et al.2002. Childhood injuries in Qatar. Middle East Journal of Emergency Medicine 2 (2). http://www.hmc.org.qa/mejem/ (accessed April 8, 2010).

Economic and Social Commission for Western Asia. 2007. National profile of the information society in the Sultanate of Oman. United Nations. http://www.escwa. un.org/wsis/reports/docs/Oman-07-E.pdf (accessed April 8, 2010).

Jenkins, G. to A. S. Weber 2009. Personal communication. August 22.

Jolo, H. A. 2007. Educational outcomes and labor market based on supply and demand: A Qatari perspective. In World Sustainable Development Outlook 2007, ed. A. Ahmed, 44-51. Sheffield: Greenleaf.

Ghaleb, Fayed F. M. et al. 2006. A web-based e-learning system using semantic web framework. Journal of Computer Science 2 (8):619-626.

Gonzalez, G. et al. 2008. Facing Human Capital Challenges of the 21st Century: Education and Labor Market Initiatives in Lebanon, Oman, Qatar, and the United Arab Emirates. Santa Monica: RAND.

Government of Qatar Planning Council. 2007. Turning Qatar into a Competitive Knowledge-Based Economy: Knowledge Economy Assessment of Qatar. Doha: Government of Qatar.

Guessoum, N. 2006. Online learning in the Arab world. eLearn Magazine. http:// www.elearnmag.org/subpage.cfm?section=articles\&article=40-1 (accessed April 8, 2010).

Gulf Times. 2006. E-learning project starts at girls' school in Wakrah. September 14. http://www.gulf-times.com/site/topics/article.asp?cu_no=2\&item _ no=107708\&version=1\&template_id=36\&parent_id=16 (accessed April 8, 2010).

Heji, H. 2007. The Aspects of American Doctoral Educational Leadership Programs Utilized in the Construction of a Culturally Sensitive Proposal for a Qatari Doctoral 
Educational Leadership Program. Doctoral dissertation, St. Josephs University.

Hofstede, G. 1986. Cultural differences in learning and teaching. International Journal of Intercultural Relations 10 (3):301-20.

. 2001. Culture's Consequences: Comparing Values, Behaviors, Institutions, and Organizations Across Nations. $2^{\text {nd }}$ ed. London: Sage.

Hussein, M. I. et al. 2007. Evaluation of IT-based active learning project at the UAE University College of Engineering case study. Emirates Journal for Engineering Research 12 (1):37-42.

ictQatar. 2007. Nurturing knowledge. ICT Today. http:/www.ict.gov.qa/files/ images/Nurturing\%20Knowledge\%20EN.pdf (accessed April 8, 2010).

2009. Qatar's ICT landscape 2009: Assessment of information communication technology in Qatar. Doha: Supreme Council of Information and Communication Technology.

Internet World Stats. 2009. http://www.internetworldstats.com/ (accessed April 8, 2010).

Kandil, S. et al. 2004. Creating the cadre for distant teaching and training; A case study from Arabian Gulf University and University of Sunderland. Paper presented at the Global Integration of Graduate Programmes Conference GIGP November 26-30, Amman, Jordan.

Laaser, W. 2006. Virtual universities for African and Arab countries. Turkish Online Journal of Distance Education 7 (4):147-160.

Lansari, A., A. Tubaishat, and A. Al-Rawi. 2007. Using an outcome-based information technology curriculum and an e-learning platform to facilitate student learning. Issues in Informing Science and Information Science 4:461-471.

Manibo, Medilyn. 2007. MTC-Vodafone (Bahrain) e-learning center leads the way to higher education. AMEinfo, May 2. http://www.ameinfo.com/118785.html (accessed July 12, 2009).

Manochehr, Naser-Nick. 2006. The influence of learning styles on learners in e-learning environments: An empirical study. Computers in Higher Education Economics Review 18 (1):10-14.

Means, B. et al. 2009. Evaluation of Evidence-Based Practices in Online Learning: A Meta-Analysis and Review of Online Learning Studies. Washington, D.C.: U.S. 
Department of Education, Office of Planning, Evaluation, and Policy Development.

Middle East North Africa-Financial Network. 2008. KSA's eLearning industry to touch $\$ 125 \mathrm{~m}$ in 2008. http://www.menafn.com/qn_news_story_s. asp?StoryId=1093194010 (accessed April 8, 2010).

Mohamed, A. A. H. 2005. Distance higher education in the Arab region: The need for quality assurance frameworks. Online Journal of Distance Learning Administration $8(1): 1-11$.

Mohammad, I. 1992. Education in the State of Qatar in the 20th Century. Revised M. M. Abu-Hashem. Doha: Ministry of Education.

Moussa, Nabil and Sandra Moussa. 2008. Quality assurance of e-learning in developing countries. Non-linear Analysis 71, e32-e34.

Naji, K. 1976. Education in Qatar in the first half of the $20^{\text {th }}$ Century. Historical Studies Conference on Eastern Arabia. Doha, Qatar.

Olayiwola, Noimot. 2009. Sidra to offer health solutions on mobiles. Gulf Times. March 3. http://www.gulf-times.com/site/topics/article.asp?cu_no=2\&item_ no=278943\&version=1\&template_id=36\&parent_id=16 (accessed April 8, 2010).

Prowse, J. K. 2007. The Influence of Culture on Pedagogy: A Case Study Comparing Pedagogical Practices in a Transnational Business Program in Qatar with its Canadian Home Institution. Doctoral dissertation, University of Calgary, Alberta.

Reilly, B. 2008. Digital encounters: Using information technology in an overseas branch campus. The History Teacher 41 (4):53-41.

Sereno, S. et al. 2007. Telementoring for minimally invasive surgical training by wireless robot. Surgical Innovation 14 (3):184-91.

Sidra Medical and Research Center. 2009. Project Update. http://www.sidra.org/en/ Pages/Default.aspx (accessed April 8, 2010).

Stasz, C. et al. 2007. Post-Secondary Education in Qatar: Employer Demand, Student Choice, and Options for Policy. Santa Monica: Rand-Qatar Policy Institute.

Sultanate ofOmanInformation TechnologyAuthority.2007.Omandigitalsocietyreport. http://www.ita.gov.om/ITAPortal/Data/DocLibrary/FID2007113164424937/ Digita_Omanl_society_Report.pdf (accessed April 8, 2010). 
TechBridgeWorld. 2009. Innovative student technology experience. http://www. techbridgeworld.org/istep/\#overview (accessed April 8, 2010).

Texas AEM Engineering News. 2008. Schlumberger, Texas A\&M at Qatar partner for training for professionals in oil and gas industry, August 13. http://engineering. tamu.edu/news/index.php (accessed April 8, 2010).

UNESCO. 2002. Globalization and Higher Education: Case Study—Arab States. Paris: UNESCO.

Weber, A. S. 1996. Electronic Shakespeare. Binghamton: State University of New York, Binghamton. http://lists.village.virginia.edu/lists_archive/Humanist/ v10/0374.html (accessed April 13, 2010).

2009a. E-learning in the Gulf Cooperation Council (GCC) countries: Problems and prospects. In Web Based Education (WBE 2009), ed. V. Uskov. Calgary: IASTED.

.2009b. Arabic speakers' use of English language course management systems: Angel, Moodle, Blackboard. unpublished research.

2010. E-learning: A necessity for the overseas branch campus student. Proceedings of 2010 International Joint Conferences on e-CASE and e-Technology, January 8-10. Macau.

Weber, A. S. and Musson D. M. 2010. Educational considerations in the development of e-health systems in the Gulf Cooperation Council (GCC) countries. In Web Based Education (WBE 2010), ed. V. Uskov. Calgary: IASTED.

Weill Cornell Medical College in Qatar. 2009. Weill Cornell Medical College in Qatar. http://qatar-weill.cornell.edu/index.html (accessed April 8, 2010).

World Economic Forum. 2009. Networked readiness rankings 2008-09. Global Technology Report 2008-09. http://www.weforum.org/en/index.htm (accessed April 8, 2010).

Yousif, A. 2007. Personal experience on online mediated learning courses both at Qatar and Maryland University. In Proceedings Learning Technologies and Mathematics Middle East Conference. Muscat, Oman: Sultan Qaboos University. 


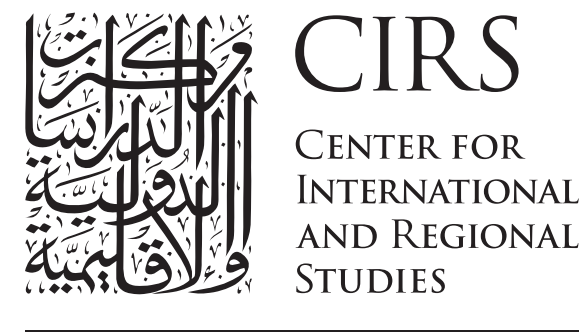

\section{GEORGETOWN UNIVERSITY} SCHOOL OF FOREIGN SERVICE IN QATAR

Center for International and Regional Studies Georgetown University School of Foreign Service in Qatar P.O. Box 23689

Doha, Qatar

http://cirs.georgetown.edu

Tel +97444578400

Fax +97444578401 


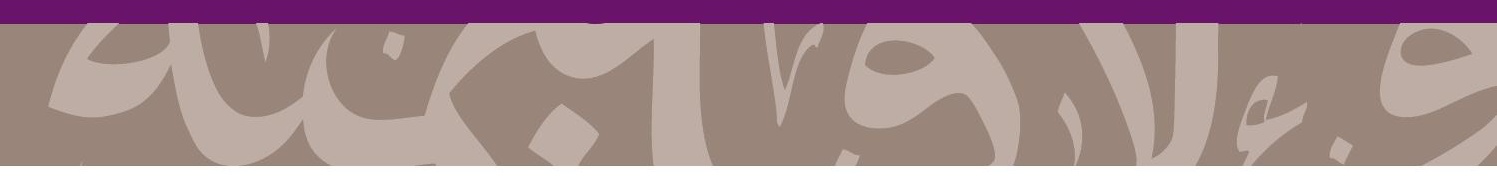

